\title{
Predictive outcome factors in the young patient treated with lumbar disc herniation surgery
}

\author{
Fredrik Strömqvist, MD, ${ }^{1}$ Björn Strömqvist, MD, PhD, ${ }^{1}$ Bo Jönsson, MD, PhD,1 \\ Paul Gerdhem, MD, PhD, ${ }^{2}$ and Magnus K. Karlsson, MD, PhD'
}

\begin{abstract}
${ }^{1}$ Clinical and Molecular Osteoporosis Research Unit, Departments of Clinical Sciences and Orthopaedics, Lund University, Skane University Hospital, Malmö; and 'Department of Orthopaedics, Karolinska University Hospital and Department of Clinical Sciences, Intervention and Technology, Karolinska Institutet, Stockholm, Sweden
\end{abstract}

\begin{abstract}
OBJECTIVE The aim of this study was to evaluate predictive factors for outcome after lumbar disc herniation surgery in young patients.

METHODS In the national Swedish spine register, the authors identified 180 patients age 20 years or younger, in whom preoperative and 1-year postoperative data were available. The cohort was treated with primary open surgery due to lumbar disc herniation between 2000 and 2010. Before and 1 year after surgery, the patients graded their back and leg pain on a visual analog scale, quality of life by the 36-Item Short-Form Health Survey and EuroQol-5 Dimensions, and disability by the Oswestry Disability Index. Subjective satisfaction rate was registered on a Likert scale (satisfied, undecided, or dissatisfied). The authors evaluated if age, sex, preoperative level of leg and back pain, duration of leg pain, pain distribution, quality of life, mental status, and/or disability were associated with the outcome. The primary end point variable was the grade of patient satisfaction.
\end{abstract}

RESULTS Lumbar disc herniation surgery in young patients normalizes quality of life according to the 36-Item ShortForm Health Survey, and only $4.5 \%$ of the patients were unsatisfied with the surgical outcome. Predictive factors for inferior postoperative patient-reported outcome measures (PROM) scores were severe preoperative leg or back pain, low preoperative mental health, and pronounced preoperative disability, but only low preoperative mental health was associated with inferiority in the subjective grade of satisfaction. No associations were found between preoperative duration of leg pain, distribution of pain, or health-related quality of life and the postoperative PROM scores or the subjective grade of satisfaction.

CONCLUSIONS Lumbar disc herniation surgery in young patients generally yields a satisfactory outcome. Severe preoperative pain, low mental health, and severe disability increase the risk of reaching low postoperative PROM scores, but are only of relevance clinically (low subjective satisfaction) for patients with low preoperative mental health.

http://thejns.org/doi/abs/10.3171/2016.2.SPINE16136

KEY WORDS lumbar disc herniation; outcome; prediction; PROM; surgery; patient-reported outcome measures; sex

$\mathrm{L}$ UMBAR disc herniation (LDH) has been thoroughly evaluated in adults, in respect to epidemiology, ${ }^{28}$ natural history, ${ }^{60}$ and surgical outcome. ${ }^{42,49,61}$ Due to the low incidence of LDH in children, few studies have evaluated pediatric cases. Most young patients with LDH are treated nonoperatively, and in Sweden, LDH surgery is only performed at a rate of approximately 20 per 100,000 individuals per year (www.4s.nu). Furthermore, only $3 \%$ of all LDH surgery is done in individuals below the age of 20 years, and in only $0.5 \%$ in those younger than 16 years. ${ }^{2,5,14}$, 17-19,22,26,39,41,45 With this background, it is not surprising that the surgical outcome in young patients is sparsely described. . $9,11,13-15,18,22-24,26,27,29-32,35,40,41,46,47$ Published studies are mainly retrospective, which makes the preoperative evaluation uncertain; only 1 study uses validated outcome scores,,$^{15}$ and only 1 includes more than 100 patients. ${ }^{8}$ In

ABBREVIATIONS EQ-5D = EuroQol-5 Dimensions; $L D H=$ lumbar disc herniation; $M C S$ = Mental Component Summary; ODI = Oswestry Disability Index; PROM = patient-reported outcome measures; SF-36 $=36$-Item Short-Form Health Survey; VAS = visual analog scale.

SUBMITTED January 26, 2016. ACCEPTED February 26, 2016.

INCLUDE WHEN CITING Published online May 20, 2016; DOI: 10.3171/2016.2.SPINE16136. 
young patients, if there are any predictive factors for an inferior surgical outcome, to our knowledge they are not known.

In contrast, there are studies in adults that have identified risk factors for an inferior LDH surgical outcome. . $^{34,37}$ The aim of our study was to use a prospective study design to evaluate if young patients have a risk-factor profile for an inferior surgical outcome similar to that in adults. We hypothesized that this would be the case when we asked the following: could an inferior outcome of primary surgery for LDH during youth be predicted by 1) age and sex, 2) severity of the pain, 3) duration of the pain, 4) distribution of the pain, 5) health-related quality of life, 6) mental health, and 7) grade of disability?

\section{Methods}

The National Swedish Spine Register (SweSpine) is a patient-based surgical register that includes data on a variety of lumbar spine diagnoses, including LDH. The register has previously been described in detail, and validation of the register has been found with good outcome..$^{50-53,55}$ The register has no exclusion criteria and is open to all Swedish units that perform low-back surgery to register data. Today, SweSpine covers approximately $90 \%$ of all departments performing spine surgery in Sweden. SweSpine includes pre-; peri-; and 1-, 2-, 5-, and 10-year postoperative data. The evaluations include specific questions regarding pain and function in addition to patient-reported outcome measures (PROM). In the 1-year postoperative evaluation, the subjective rate of satisfaction is registered as well as change in pain compared with the preoperative level. Surgical data are reported by the surgeon. Participation in SweSpine is voluntary for the patient and when included, patients accept that data will be used anonymously for scientific research.

In this study, we included patients 20 years or younger in whom primary LDH surgery was performed during the period between 2000 and $2010(\mathrm{n}=352)$. Eight patients with previous back surgery, 72 patients with only perioperative data, and 92 patients who did not complete the 1-year follow-up questionnaire were excluded, leaving 180 patients for this study with pre-, peri-, and 1-year postoperative data. In a drop-out analysis, we compared the preand perioperative data in those included in the study $(\mathrm{n}=$ 180) with those 92 patients with no 1-year follow-up data. We found no group differences (data not shown). All patients were treated with open discectomy, with or without microscopic assistance.

In this report, we registered sex, age at surgery, level of back and leg pain by a visual analog scale (VAS), duration of preoperative pain, consumption of analgesics, walking distance, and subjective health by the PROM, 36-Item Short-Form Health Survey (SF-36), EuroQol-5 Dimensions (EQ-5D-3 Levels), and, from 2002, also the Oswestry Disability Index (ODI). The Mental Component Summary (MCS) score in SF-36 is a summoned component for the subdomains in SF-36 that evaluate mental health. The MCS is therefore the measure used in this study to estimate mental health.

The VAS pain level is rated from 0 to 100 (where 0 rep- resents no pain and 100 the most severe pain imaginable), SF-36 from 0 to 100 (where 0 represents worst imaginable health and 100 best imaginable health), EQ-5D index from 0 to 1 (where 0 represents death and 1 full health), EuroQol visual analog scale from 0 to 100 (where 0 represents worst imaginable health and 100 best imaginable health, ${ }^{20}$ and ODI from 0 to 100 (where 0-20 represents minimal or no disability and 80-100 a bed-bound [or exaggerating] patient). The surgical data included diagnosis, operated level, operated side, and postoperative complications. At the 1-year postoperative follow-up, we registered the same data as preoperatively but also the subjective estimation of change in back and leg pain by the use of a 5-point Likert scale (pain free, pronounced improvement, slight improvement, unchanged, or deteriorated) and patient satisfaction by the use of a 3-point Likert scale (satisfied, undecided, or dissatisfied). We defined our primary outcome measurement as patient satisfaction.

We used SPSS statistics version 22 (IBM Corp.) for the statistical calculations. Descriptive data are presented as numbers, median values with ranges, mean values \pm SDs, or proportions (\%). We then divided the patients into quartiles depending on preoperative status, and compared the outcome in the different quartiles. Group comparisons were performed with the chi-square test, the Student t-test between means, and ANOVA. A p value $<0.05$ is regarded as a statistically significant difference.

\section{Results}

Preoperative background data and general outcome data are presented in Tables 1 and 2. The patients were markedly impaired before the operation, with female patients consuming more analgesics than male patients $(\mathrm{p}<$ 0.05 ). Most operations were performed on the left side and at the 2 lowest levels of the lumbar spine, with no sex differences. One patient $(0.4 \%)$ sustained a nerve root injury and 6 patients $(2.2 \%)$ a dural lesion. Surgery conferred significant improvement in all registered parameters, and to an extent that only $4.5 \%$ of the patients were unsatisfied with the outcome 1 year after surgery. No patient younger than age 18 years was unsatisfied with the surgical outcome. Outcome was virtually unchanged between 1- and 2-year follow-up.

Severe preoperative leg pain (Table 3), severe back pain (Table 4), low mental health (Table 5), and pronounced disability (Table 6) were all associated with inferior surgical outcome according to PROM. The subjective satisfaction rate was lower in patients with low preoperative mental health, whereas duration of leg pain (Supplemental Data), preponderance of leg or back pain (Supplemental Data), and health-related quality of life (Supplemental Data) were not.

\section{Discussion}

This study shows that, in general, LDH surgery in young patients yields a satisfying outcome both regarding patient satisfaction and according to PROM, where data reveal a normalized status according to SF-36. ${ }^{56}$ Improvement in PROM (VAS back and leg pain, quality of life by EQ-5D and ODI) meets previously reported predefined 
TABLE 1. Preoperative background data for age, anthropometry, operated level, and duration of pain in young patients with LDH surgery

\begin{tabular}{|c|c|c|c|c|}
\hline Variable & $\begin{array}{c}\text { All } \\
\text { Patients }\end{array}$ & Male & Female & $\begin{array}{c}\text { Sex } \\
\text { Comparison* }\end{array}$ \\
\hline $\begin{array}{l}\text { Age in yrs, me- } \\
\text { dian (range) }\end{array}$ & $19(13-20)$ & $19(15-20)$ & $19(13-20)$ & 0.83 \\
\hline $\begin{array}{l}\text { Length in cm, } \\
\text { mean (SD) }\end{array}$ & $176(10)$ & $184(6)$ & $169(6)$ & NA \\
\hline $\begin{array}{l}\text { Weight in kg, } \\
\text { mean (SD) }\end{array}$ & $72(14)$ & $78(13)$ & $67(12)$ & NA \\
\hline $\begin{array}{r}\text { BMl in } \mathrm{kg} / \mathrm{m}^{2} \\
\text { mean }(\mathrm{SD})\end{array}$ & $23(4)$ & $23(3)$ & $24(4)$ & NA \\
\hline Smoking, \% & 10 & 6 & 14 & \\
\hline Operated level, \% & & & & 0.32 \\
\hline L3-4 & 1 & 1 & 0 & \\
\hline L4-5 & 52 & 56 & 48 & \\
\hline L5-S1 & 47 & 43 & 52 & \\
\hline Operated side, \% & & & & 0.98 \\
\hline Rt & 47 & 46 & 48 & \\
\hline $\mathrm{Lt}$ & 50 & 50 & 49 & \\
\hline Bilat & 3 & 3 & 3 & \\
\hline $\begin{array}{l}\text { Consumption of } \\
\text { analgesics, \% }\end{array}$ & & & & $<0.05$ \\
\hline None & 27 & 35 & 18 & \\
\hline Intermittent & 35 & 31 & 40 & \\
\hline Regular & 38 & 34 & 42 & \\
\hline $\begin{array}{l}\text { Walking distance } \\
\text { in meters, } \%\end{array}$ & & & & 0.14 \\
\hline $0-100$ & 14 & 12 & 16 & \\
\hline $101-500$ & 14 & 16 & 13 & \\
\hline $501-1000$ & 24 & 18 & 31 & \\
\hline$>1000$ & 48 & 54 & 41 & \\
\hline $\begin{array}{l}\text { Duration of preop } \\
\text { leg pain, } \%\end{array}$ & & & & 0.21 \\
\hline $\begin{array}{l}\text { Had no leg } \\
\text { pain }\end{array}$ & 1 & 0 & 1 & \\
\hline $0-3$ mos & 10 & 13 & 7 & \\
\hline$>3-12$ mos & 54 & 56 & 53 & \\
\hline$>12-24$ mos & 24 & 19 & 30 & \\
\hline$>24$ mos & 11 & 12 & 9 & \\
\hline
\end{tabular}

$\mathrm{BMI}=$ body mass index; NA = not applicable.

* Group differences tested by chi-square, Fisher's exact, and Student's t-tests; $p<0.05$ is regarded as a statistically significant difference.

criteria defining successful outcome after LDH surgery in adults ${ }^{48}$ and the outcome is virtually unchanged between 1- and 2-year follow-up. However, preoperative severe pain, low mental health, and severe disability were factors associated with postoperative outcome in the PROM, but only low preoperative mental health was of clinical significance as the only factor also associated with an inferior postoperative subjective grade of satisfaction.

Studies have also previously evaluated the outcome of LDH surgery in children and young adults, ranging from

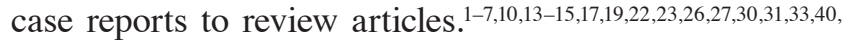
41,45,47,59,62 Most of these reported good or excellent outcome in $75 \%-100 \%$ of the cases. But despite this, the general recommendation is to start with a nonoperative approach, except in patients with a cauda equina syndrome, progressive neurological deficits, or intractable pain, where surgery is the primary recommended treatment. ${ }^{54}$ When nonoperative treatment has been unsuccessful for months, surgery is contemplated. ${ }^{34}$ But there are also surgeons who infer that surgery should be considered earlier ${ }^{17}$ because nonoperative treatment in young patients is reported with less favorable results than in adults, with a reported success rate as low as $13 \%-45 \%$. $^{13,23,30,31,58,62}$

Therefore, it would be of great interest to be aware of any preoperative factors that could predict an inferior outcome. Female sex, smoking, previous surgery, severe preoperative pain, pain duration longer than 12 months, and low mental health are known risk factors for an inferior outcome in adults, but it should be determined whether these also account for children.

In this study, a higher preoperative pain level was 1 factor associated with greater postoperative leg pain, inferior SF-36 MCS scores, and inferior ODI scores. It could, however, be debated whether these deficits are of clinical relevance because there were no postoperative group differences in EQ-5D index (the postoperative EQ-5D index was identical to or higher than that of a Swedish reference population $18-24$ years old), ${ }^{57}$ all ODI levels were below 20 (usually regarded as being a deficit of no clinical significanc ${ }^{21}$ ), and there was no difference in subjective grade of satisfaction.

Mental health, as measured by SF-36 MCS, was another preoperative factor that was associated with postoperative inferiority in most registered PROM. This was also the only preoperative risk factor that was associated with inferiority in subjective satisfaction. It is therefore of interest to note that most postoperative PROM scores in the children with the lowest preoperative mental health as measured by the SF-36 MCS were no different than in the children with the greatest preoperative pain or disability. But despite the similarity in the postoperative PROM scores, the subjective satisfaction rate was only lower in the children with low preoperative mental health (SF-36 MCS). This clearly indicates that factors beyond residual pain (VAS) or residual disability (ODI) are of importance when subjectively rating the surgical outcome during growth or adolescence.

Preoperative disability (ODI) was another predictive factor that was associated with statistically significant inferiority in most PROM scores. But the clinical relevance of categorizing young patients by grade of ODI disability should also be questioned because all young patients had a preoperative disability EQ-5D index similar to the Swedish reference population, ${ }^{57}$ all ODI levels were below $20,{ }^{21}$ and there was no difference in subjective grade of satisfaction.

Nygaard et al. reported in adults ${ }^{37}$ a less favorable outcome after LDH surgery in patients with pain duration longer than 8 months. Inferior outcome has also been reported in patients with 6-12 months of pain duration compared with individuals with less than 6 months of 
TABLE 2. Preoperative, postoperative, and 2-year follow-up data on level of pain, perceived health, and disability in young patients with LDH surgery*

\begin{tabular}{|c|c|c|c|c|}
\hline \multirow[b]{2}{*}{ Variable } & \multicolumn{3}{|c|}{ All 180 Patients } & \multirow[b]{2}{*}{2 Yrs Postop (99 patients) } \\
\hline & Preop & Postop & Improvement & \\
\hline \multicolumn{5}{|l|}{ VAS score } \\
\hline Leg pain & $63(59-67)$ & $13(10-17)$ & $50(45-55)$ & $13(9-18)$ \\
\hline Back pain & $40(35-45)$ & $16(13-20)$ & $25(19-31)$ & $18(13-22)$ \\
\hline$E Q-5 D$ index & $0.35(0.29-0.41)$ & $0.82(0.78-0.86)$ & $0.48(0.41-0.54)$ & $0.80(0.76-0.85)$ \\
\hline EQ VAS score & $52(48-55)$ & $79(76-83)$ & $28(24-32)$ & $79(75-83)$ \\
\hline \multicolumn{5}{|l|}{ SF-36 score } \\
\hline PCS & $38.8(36.9-40.8)$ & $47.3(45.6-49.1)$ & $8.5(6.1-11.0)$ & $47.2(45.2-49.2)$ \\
\hline MCS & $34.8(33.1-36.5)$ & $49.5(47.9-51.0)$ & $15.5(13.8-17.3)$ & $49.1(47.4-50.9)$ \\
\hline ODI score & $34(32-37)$ & $11(9-13)$ & $24(21-27)$ & $11(9-14)$ \\
\hline
\end{tabular}

PCS = Physical Component Summary.

* Data are presented as mean values with $95 \% \mathrm{Cl}$ in parentheses, with changes between pre- and postoperative values tested by paired Student's t-tests. Statistically significant improvements are presented in boldface type.

duration. ${ }^{38}$ Similar conclusions have been drawn by others, ${ }^{25}$ and LDH surgery in adults is in general reported with a superior outcome if being conducted with less than 12 months of pain duration. . $2,16,25,36,43,44$ In contrast, the preoperative duration of pain seems to be of no clinical relevance in younger patients. That is, long-standing pain in children, adolescents, and young adults should not be a contraindication for surgery.

Study strengths include the evaluation of LDH surgery in children, adolescents, and young adults with the largest study population included to date, the first to prospectively include preoperative data, and the second to use validated PROM that make comparison across studies possible. The study also captures the outcome in the general health care system, because the cohort includes children operated on in various hospitals, with different techniques, and by different surgeons with varying levels of competence and experience. By using this study design, we could present the outcome of pediatric LDH surgery nationwide versus only in highly specialized pediatric units.

TABLE 3. One-year postoperative outcomes in level of back and leg pain, perceived health, and disability in relation to preoperative severity of leg pain*

\begin{tabular}{|c|c|c|c|c|c|}
\hline \multirow[b]{2}{*}{ Variable } & \multicolumn{4}{|c|}{ Preop Quartiles of Leg Pain (VAS) } & \multirow{2}{*}{$\begin{array}{l}p \text { Value for Group } \\
\text { Comparisons }\end{array}$} \\
\hline & Quartile 1 (worst) & Quartile 2 & Quartile 3 & Quartile 4 (least) & \\
\hline No. of patients & 43 & 44 & 43 & 44 & \\
\hline Median age at op, yrs (range) & $19(15-20)$ & $18.5(16-20)$ & $19(16-20)$ & $19(13-20)$ & 0.90 \\
\hline Sex, $\%$ & & & & & 0.40 \\
\hline $\mathrm{F}$ & 49 & 55 & 58 & 41 & \\
\hline M & 51 & 45 & 42 & 59 & \\
\hline \multicolumn{6}{|l|}{ Postop 1-yr outcomes } \\
\hline \multicolumn{6}{|l|}{ VAS score } \\
\hline Leg pain & $18(9-26)$ & $16(10-23)$ & $10(4-15)$ & $7(2-12)$ & $<0.05$ \\
\hline Back pain & $18(10-26)$ & $21(14-28)$ & $12(5-18)$ & $12(5-18)$ & 0.06 \\
\hline EQ-5D index & $0.80(0.71-0.88)$ & $0.78(0.70-0.86)$ & $0.89(0.82-0.95)$ & $0.85(0.77-0.92)$ & 0.19 \\
\hline EQ VAS score & $80.6(74.3-87.0)$ & $74.4(66.6-82.2)$ & $82.2(76.3-88.2)$ & $80.4(73.9-86.9)$ & 0.26 \\
\hline \multicolumn{6}{|l|}{ SF-36 score } \\
\hline PCS & $48.4(45.0-51.9)$ & $46.6(43.1-50.1)$ & $49.0(45.6-52.5)$ & $46.2(41.8-50.5)$ & 0.60 \\
\hline MCS & $49.1(46.5-51.7)$ & $46.8(43.5-50.0)$ & $51.0(47.7-54.3)$ & $52.2(49.1-55.2)$ & $<0.05$ \\
\hline ODI score & $12(8-16)$ & $14(9-19)$ & $8(4-12)$ & $7(4-11)$ & $<0.05$ \\
\hline Satisfaction rate, \% & & & & & 0.16 \\
\hline Satisfied & 81 & 77 & 91 & 95 & \\
\hline Undecided & 12 & 16 & 9 & 2 & \\
\hline Unsatisfied & 7 & 7 & 0 & 2 & \\
\hline
\end{tabular}

* Data are presented as numbers, mean values with $95 \% \mathrm{Cl}$ in parentheses, or proportions, with group differences tested by ANOVA. $p<0.05$ is regarded as a statistically significant difference. 
TABLE 4. One-year postoperative outcomes in level of back and leg pain, perceived health, and disability in relation to preoperative severity of back pain*

\begin{tabular}{|c|c|c|c|c|c|}
\hline \multirow[b]{2}{*}{ Variable } & \multicolumn{4}{|c|}{ Preop Quartiles of Back Pain (VAS) } & \multirow{2}{*}{$\begin{array}{l}p \text { Value for Group } \\
\text { Comparisons }\end{array}$} \\
\hline & Quartile 1 (worst) & Quartile 2 & Quartile 3 & Quartile 4 (least) & \\
\hline No. of patients & 43 & 44 & 44 & 44 & \\
\hline Median age at op, yrs (range) & $19(14-20)$ & $19(16-20)$ & $19(13-20)$ & $18(16-20)$ & 0.54 \\
\hline Sex, $\%$ & & & & & 0.08 \\
\hline $\mathrm{F}$ & 61 & 57 & 36 & 43 & \\
\hline M & 39 & 43 & 64 & 57 & \\
\hline \multicolumn{6}{|l|}{ Postop 1-yr outcomes } \\
\hline \multicolumn{6}{|l|}{ VAS score } \\
\hline Leg pain & $16(9-24)$ & $17(9-25)$ & $8(4-11)$ & $9(4-15)$ & $<0.05$ \\
\hline Back pain & $21(12-30)$ & $19(12-26)$ & $12(7-18)$ & $10(4-17)$ & $<0.05$ \\
\hline$E Q-5 D$ index & $0.80(0.72-0.88)$ & $0.80(0.72-0.88)$ & $0.85(0.79-0.91)$ & $0.86(0.78-0.94)$ & 0.51 \\
\hline EQ VAS score & $76.7(69.2-84.2)$ & $73.8(66.0-81.6)$ & $83.9(79.6-88.3)$ & $83.9(78.2-89.5)$ & 0.05 \\
\hline \multicolumn{6}{|l|}{ SF-36 score } \\
\hline PCS & $46.0(42.4-49.7)$ & $47.8(44.3-51.2)$ & $48.3(44.9-51.7)$ & $47.9(43.6-52.2)$ & 0.32 \\
\hline MCS & $47.9(44.6-51.1)$ & $47.4(44.3-50.4)$ & $51.0(48.0-54.0)$ & $53.0(50.1-55.8)$ & $<0.001$ \\
\hline ODI score & $14(9-19)$ & $11(7-15)$ & $10(6-14)$ & $7(3-10)$ & $<0.05$ \\
\hline Satisfaction rate, $\%$ & & & & & 0.34 \\
\hline Satisfied & 84 & 80 & 91 & 88 & \\
\hline Undecided & 7 & 16 & 9 & 7 & \\
\hline Unsatisfied & 9 & 5 & 0 & 5 & \\
\hline
\end{tabular}

* Data are presented as numbers, mean values with $95 \% \mathrm{Cl}$ in parentheses, or proportions, with group differences tested by ANOVA. $p<0.05$ is regarded as a statistically significant difference.

TABLE 5. One-year postoperative outcomes in level of back and leg pain, perceived health, and disability in relation to preoperative mental health*

\begin{tabular}{|c|c|c|c|c|c|}
\hline \multirow[b]{2}{*}{ Variable } & \multicolumn{4}{|c|}{ Preop Mental Health (evaluated by SF-36 MCS) } & \multirow{2}{*}{$\begin{array}{l}p \text { Value for Group } \\
\text { Comparisons }\end{array}$} \\
\hline & Quartile 1 (worst) & Quartile 2 & Quartile 3 & Quartile 4 (best) & \\
\hline No. of patients & 42 & 43 & 43 & 43 & \\
\hline Median age at op, yrs (range) & $19(16-20)$ & $19(14-20)$ & $19(15-20)$ & $18(16-20)$ & 0.33 \\
\hline Sex, \% & & & & & 0.06 \\
\hline $\mathrm{F}$ & 62 & 49 & 51 & 67 & \\
\hline M & 38 & 51 & 49 & 33 & \\
\hline \multicolumn{6}{|l|}{ Postop 1-yr outcomes } \\
\hline \multicolumn{6}{|l|}{ VAS score } \\
\hline Leg pain & $18(10-26)$ & $11(5-16)$ & $10(5-16)$ & $12(5-20)$ & 0.07 \\
\hline Back pain & $23(14-32)$ & $14(7-21)$ & $15(9-22)$ & $9(5-14)$ & $<0.05$ \\
\hline EQ 5D index & $0.72(0.63-0.82)$ & $0.86(0.80-0.92)$ & $0.84(0.76-0.92)$ & $0.88(0.84-0.93)$ & $<0.05$ \\
\hline EQ VAS score & $69.7(62.1-77.3)$ & $81.6(74.5-88.6)$ & $82.8(77.3-88.4)$ & $86.7(82.8-90.6)$ & $<0.001$ \\
\hline \multicolumn{6}{|l|}{ SF-36 score } \\
\hline PCS & $44.0(39.5-48.4)$ & $49.1(45.7-52.4)$ & $49.0(45.7-52.3)$ & $49.1(46.3-51.9)$ & $<0.05$ \\
\hline MCS & $43.3(40.0-46.5)$ & $51.6(49.5-53.8)$ & $51.0(48.0-54.0)$ & $54.6(51.9-57.3)$ & $<0.001$ \\
\hline ODI score & $17(12-21)$ & $8(5-12)$ & $9(6-13)$ & $6(3-8)$ & $<0.001$ \\
\hline Satisfaction rate, \% & & & & & $<0.05$ \\
\hline Satisfied & 71 & 91 & 84 & 95 & \\
\hline Undecided & 15 & 7 & 14 & 5 & \\
\hline Unsatisfied & 15 & 2 & 2 & 0 & \\
\hline
\end{tabular}

* Data are presented as numbers, mean values with $95 \% \mathrm{Cl}$ in parentheses, or proportions, with group differences tested by ANOVA. $p<0.05$ is regarded as a statistically significant difference. 
TABLE 6. One-year postoperative outcomes in level of back and leg pain, perceived health, and disability in relation to preoperative disability*

\begin{tabular}{|c|c|c|c|c|c|}
\hline \multirow[b]{2}{*}{ Variable } & \multicolumn{4}{|c|}{ Preop Disability (evaluated by ODI) } & \multirow{2}{*}{$\begin{array}{l}p \text { Value for Group } \\
\text { Comparisons }\end{array}$} \\
\hline & Quartile 1 (worst) & Quartile 2 & Quartile 3 & Quartile 4 (least) & \\
\hline No. of patients & 37 & 36 & 36 & 36 & \\
\hline Median age at op, yrs (range) & $18(16-20)$ & $19(17-20)$ & $19(14-20)$ & $18(15-20)$ & 0.25 \\
\hline Sex, \% & & & & & 0.25 \\
\hline $\mathrm{F}$ & 57 & 47 & 44 & 33 & \\
\hline M & 43 & 53 & 56 & 67 & \\
\hline \multicolumn{6}{|l|}{ Postop 1-yr outcomes } \\
\hline \multicolumn{6}{|l|}{ VAS score } \\
\hline Leg pain & $16(9-25)$ & $13(6-20)$ & $12(6-19)$ & $11(4-17)$ & 0.57 \\
\hline Back pain & $27(17-37)$ & $15(8-21)$ & $11(6-15)$ & $12(5-19)$ & $<0.001$ \\
\hline$E Q-5 D$ index & $0.74(0.65-0.84)$ & $0.77(0.67-0.86)$ & $0.88(0.84-0.93)$ & $0.88(0.82-0.94)$ & $<0.05$ \\
\hline EQ VAS score & $71.6(63.7-79.6)$ & $79.0(71.3-86.7)$ & $83.1(77.7-88.4)$ & $82.9(77.1-88.8)$ & 0.06 \\
\hline \multicolumn{6}{|l|}{ SF-36 score } \\
\hline PCS & $45.3(41.5-49.1)$ & $44.7(40.2-49.3)$ & $49.1(45.6-52.6)$ & $49.6(46.6-52.5)$ & 0.09 \\
\hline MCS & $45.6(42.6-48.6)$ & $49.2(45.6-52.7)$ & $51.2(48.4-54.0)$ & $51.9(48.8-55.1)$ & $<0.05$ \\
\hline ODI score & $17(12-22)$ & $11(7-16)$ & $8(5-11)$ & $7(3-10)$ & $<0.001$ \\
\hline Satisfaction rate, $\%$ & & & & & 0.70 \\
\hline Satisfied & 78 & 83 & 89 & 80 & \\
\hline Undecided & 11 & 14 & 8 & 14 & \\
\hline Unsatisfied & 11 & 3 & 3 & 6 & \\
\hline
\end{tabular}

* Data are presented as numbers, mean values with $95 \% \mathrm{Cl}$ in parentheses, or proportions, with group differences tested by ANOVA. $p<0.05$ is regarded as a statistically significant difference.

Weaknesses of this study include the incomplete postoperative data collection. However, the drop-out analyses indicate that there was no selection bias. It was also advantageous to have data from even younger children and outcome in nonoperatively treated patients. Another weakness is that the EQ-5D index is only validated in adults, but because the mean age in our cohort was 18-19 years, it seems acceptable to compare our data with existing normative EQ-5D data in individuals 18-24 years old. It would have been of interest to have age- and country-specific normative data for comparison in ODI (however, these have never been reported in any study) and other possible risk factors such as smoking, alcohol consumption, psychosocial risk factors, and/or previous surgery registered. It could also be debated whether the MCS score in SF-36 is the best measure of mental health. It would have been beneficial to have information on radiological findings, type and length of nonoperative treatment before surgery was performed, reason for selecting the patient for surgery, and surgeonspecific factors such as specialty of the operating surgeon, experience, and annual surgical volumes; however, such data are not available in SweSpine.

\section{Conclusions}

Lumbar disc herniation surgery in young patients generally yields a satisfactory outcome. Low preoperative mental health is a risk factor for reaching a subjective unsatisfying outcome. Severe preoperative pain, low mental health, and severe disability are risk factors for reaching lower postoperative PROM scores.

\section{References}

1. Bartolozzi P, Lombardini G, Floris G: Herniated lumbar disc in the child: a description of two cases. Ital J Orthop Traumatol 15:116-120, 1989

2. Beks JW, ter Weeme CA: Herniated lumbar discs in teenagers. Acta Neurochir (Wien) 31:195-199, 1975

3. Benifla M, Melamed I, Barrelly R, Aloushin A, Shelef I: Unilateral partial hemilaminectomy for disc removal in a 1-yearold child. J Neurosurg Pediatr 2:133-135, 2008

4. Börgersen SE: Proceedings: Herniation of the lumbar intervertebral disc in children and adolescents. Acta Neurochir (Wien) 31:272-273, 1975

5. Borgesen SE, Vang PS: Herniation of the lumbar intervertebral disk in children and adolescents. Acta Orthop Scand 45:540-549, 1974

6. Bradford DS, Garcia A: Herniations of the lumbar intervertebral disk in children and adolescents. A review of 30 surgically treated cases. JAMA 210:2045-2051, 1969

7. Bradford DS, Garcia A: Lumbar intervertebral disk herniations in children and adolescents. Orthop Clin North Am 2:583-592, 1971

8. Cahill J, Frost G, Solanki GA: Paediatric lumbar disc herniation in the very young: a case-based update. Childs Nerv Syst 27:687-691, 2011

9. Chen LH, Chang CH, Lee ZL, Niu CC, Lai PL, Tan CF, et al: Intervertebral disc herniation in adolescents. Chang Gung Med J 27:22-28, 2004

10. Clarke NM, Cleak DK: Intervertebral lumbar disc prolapse in children and adolescents. J Pediatr Orthop 3:202-206, 1983

11. Dang L, Liu Z: A review of current treatment for lumbar disc herniation in children and adolescents. Eur Spine J 19:205214,2010

12. Dauch WA, Fasse A, Brücher K, Bauer BL: [Predictors of treatment success after microsurgical operation of lumbar 
intervertebral disk displacement.] Zentralbl Neurochir 55:144-155, 1994 (Ger)

13. DeLuca PF, Mason DE, Weiand R, Howard R, Bassett GS: Excision of herniated nucleus pulposus in children and adolescents. J Pediatr Orthop 14:318-322, 1994

14. DeOrio JK, Bianco AJ Jr: Lumbar disc excision in children and adolescents. J Bone Joint Surg Am 64:991-996, 1982

15. Durham SR, Sun PP, Sutton LN: Surgically treated lumbar disc disease in the pediatric population: an outcome study. $\mathbf{J}$ Neurosurg 92 (1 Suppl):1-6, 2000

16. Dvorak J, Gauchat MH, Valach L: The outcome of surgery for lumbar disc herniation. I. A 4-17 years' follow-up with emphasis on somatic aspects. Spine (Phila Pa 1976) 13:1418-1422, 1988

17. Ebersold MJ, Quast LM, Bianco AJ Jr: Results of lumbar discectomy in the pediatric patient. J Neurosurg 67:643647, 1987

18. Epstein JA, Epstein NE, Marc J, Rosenthal AD, Lavine LS: Lumbar intervertebral disk herniation in teenage children: recognition and management of associated anomalies. Spine (Phila Pa 1976) 9:427-432, 1984

19. Epstein JA, Lavine LS: Herniated lumbar intervertebral discs in teen-age children. J Neurosurg 21:1070-1075, 1964

20. EuroQol Group: EuroQol-a new facility for the measurement of health-related quality of life. Health Policy 16:199208, 1990

21. Fairbank JC, Pynsent PB: The Oswestry Disability Index. Spine (Phila Pa 1976) 25:2940-2952, 2000

22. Fisher RG, Saunders RL: Lumbar disc protrusion in children. J Neurosurg 54:480-483, 1981

23. Gennuso R, Humphreys RP, Hoffman HJ, Hendrick EB, Drake JM: Lumbar intervertebral disc disease in the pediatric population. Pediatr Neurosurg 18:282-286, 1992

24. Haidar R, Ghanem I, Saad S, Uthman I: Lumbar disc herniation in young children. Acta Paediatr 99:19-23, 2010

25. Hurme M, Alaranta H: Factors predicting the result of surgery for lumbar intervertebral disc herniation. Spine (Phila Pa 1976) 12:933-938, 1987

26. Ishihara H, Matsui H, Hirano N, Tsuji H: Lumbar intervertebral disc herniation in children less than 16 years of age. Long-term follow-up study of surgically managed cases. Spine (Phila Pa 1976) 22:2044-2049, 1997

27. Kamel M, Rosman M: Disc protrusion in the growing child. Clin Orthop Relat Res (185):46-52, 1984

28. Kelsey JL: An epidemiological study of acute herniated lumbar intervertebral discs. Rheumatol Rehabil 14:144-159, 1975

29. Kumar R, Kumar V, Das NK, Behari S, Mahapatra AK: Adolescent lumbar disc disease: findings and outcome. Childs Nerv Syst 23:1295-1299, 2007

30. Kurihara A, Kataoka O: Lumbar disc herniation in children and adolescents. A review of 70 operated cases and their minimum 5-year follow-up studies. Spine (Phila Pa 1976) 5:443-451, 1980

31. Kurth AA, Rau S, Wang C, Schmitt E: Treatment of lumbar disc herniation in the second decade of life. Eur Spine J 5:220-224, 1996

32. Lagerbäck T, Elkan P, Möller H, Grauers A, Diarbakerli E, Gerdhem P: An observational study on the outcome after surgery for lumbar disc herniation in adolescents compared with adults based on the Swedish Spine Register. Spine J 15:1241-1247, 2015

33. MacGee EE: Protruded lumbar disc in a 9-year-old boy. $\mathbf{J}$ Pediatr 73:418-419, 1968

34. Manniche C, Asmussen KH, Vinterberg H, Rose-Hansen EB, Kramhøft J, Jordan A: Analysis of preoperative prognostic factors in first-time surgery for lumbar disc herniation, including Finneson's and modified Spengler's score systems. Dan Med Bull 41:110-115, 1994
35. Martínez-Lage JF, Fernández Cornejo V, López F, Poza M: Lumbar disc herniation in early childhood: case report and literature review. Childs Nerv Syst 19:258-260, 2003

36. Ng LC, Sell P: Predictive value of the duration of sciatica for lumbar discectomy. A prospective cohort study. J Bone Joint Surg Br 86:546-549, 2004

37. Nygaard OP, Kloster R, Solberg T: Duration of leg pain as a predictor of outcome after surgery for lumbar disc herniation: a prospective cohort study with 1-year follow up. J Neurosurg 92 (2 Suppl):131-134, 2000

38. Nygaard OP, Romner B, Trumpy JH: Duration of symptoms as a predictor of outcome after lumbar disc surgery. Acta Neurochir (Wien) 128:53-56, 1994

39. O'Connell JE: Intervertebral disk protrusions in childhood and adolescence. Br J Surg 47:611-616, 1960

40. Papagelopoulos PJ, Shaughnessy WJ, Ebersold MJ, Bianco AJ Jr, Quast LM: Long-term outcome of lumbar discectomy in children and adolescents sixteen years of age or younger. $\mathbf{J}$ Bone Joint Surg Am 80:689-698, 1998

41. Parisini P, Di Silvestre M, Greggi T, Miglietta A, Paderni $\mathrm{S}$ : Lumbar disc excision in children and adolescents. Spine (Phila Pa 1976) 26:1997-2000, 2001

42. Peul WC, van Houwelingen HC, van den Hout WB, Brand R, Eekhof JA, Tans JT, et al: Surgery versus prolonged conservative treatment for sciatica. N Engl J Med 356:2245-2256, 2007

43. Postacchini F: Management of herniation of the lumbar disc. J Bone Joint Surg Br 81:567-576, 1999

44. Rothoerl RD, Woertgen C, Brawanski A: When should conservative treatment for lumbar disc herniation be ceased and surgery considered? Neurosurg Rev 25:162-165, 2002

45. Rugtveit A: Juvenile lumbar disc herniations. Acta Orthop Scand 37:348-356, 1966

46. Shillito J Jr: Pediatric lumbar disc surgery: 20 patients under 15 years of age. Surg Neurol 46:14-18, 1996

47. Smorgick Y, Floman Y, Millgram MA, Anekstein Y, Pekarsky I, Mirovsky Y: Mid- to long-term outcome of disc excision in adolescent disc herniation. Spine J 6:380-384, 2006

48. Solberg T, Johnsen LG, Nygaard OP, Grotle M: Can we define success criteria for lumbar disc surgery?: estimates for a substantial amount of improvement in core outcome measures. Acta Orthop 84:196-201, 2013

49. Spangfort EV: The lumbar disc herniation. A computer-aided analysis of 2,504 operations. Acta Orthop Scand Suppl 142:1-95, 1972

50. Strömqvist B: Evidence-based lumbar spine surgery. The role of national registration. Acta Orthop Scand Suppl 73:3439,2002

51. Strömqvist B, Fritzell P, Hägg O, Jönsson B: One-year report from the Swedish National Spine Register. Acta Orthop Suppl 76:1-24, 2005

52. Strömqvist B, Fritzell P, Hägg O, Jönsson B, Sandén B: Swespine: the Swedish Spine Register: the 2012 report. Eur Spine J 22:953-974, 2013

53. Strömqvist B, Fritzell P, Hägg O, Jönsson B: The Swedish Spine Register: development, design and utility. Eur Spine J 18 (Suppl 3):294-304, 2009

54. Strömqvist B, Hedlund R, Jönsson B, Tullberg T: [Lumbar diseases.] Lakartidningen 104:1498-1502, 2007 (Swedish)

55. Strömqvist B, Jönsson B, Fritzell P, Hägg O, Larsson BE, Lind B: The Swedish National Register for lumbar spine surgery: Swedish Society for Spinal Surgery. Acta Orthop Scand 72:99-106, 2001

56. Sullivan M, Karlsson J, Ware JE: SF-36 Hälsoenkät: Svensk Manual och Tolkningsguide. Gothenburg: Sahlgrenska University Hospital, 1994

57. Szende A, Janssen B, Cabases J: Self-Reported Population Health: An International Perspective Based on EQ-5D. Dordrecht: Springer, 2014, pp 210 
58. Taylor TKF: Intervertebral disc prolapse in children and adolescents. J Bone Joint Surg Br 53:357, 1971

59. Wahren H: Herniated nucleus pulposus in a child of twelve years. Acta Orthop Scand 16:40-42, 1945

60. Weber H: The natural course of disc herniation. Acta Orthop Scand Suppl 251:19-20, 1993

61. Weinstein JN, Tosteson TD, Lurie JD, Tosteson AN, Hanscom B, Skinner JS, et al: Surgical vs nonoperative treatment for lumbar disk herniation: the Spine Patient Outcomes Research Trial (SPORT): a randomized trial. JAMA 296:24412450, 2006

62. Zamani MH, MacEwen GD: Herniation of the lumbar disc in children and adolescents. J Pediatr Orthop 2:528-533, 1982

\section{Disclosures}

The authors report no conflict of interest concerning the materials or methods used in this study or the findings specified in this paper.

\section{Author Contributions}

Conception and design: F Strömqvist, Gerdhem, Karlsson. Acqui- sition of data: Karlsson. Analysis and interpretation of data: all authors. Drafting the article: all authors. Critically revising the article: B Strömqvist, Jönsson. Reviewed submitted version of manuscript: B Strömqvist, Jönsson, Gerdhem, Karlsson. Approved the final version of the manuscript on behalf of all authors: F Strömqvist. Statistical analysis: F Strömqvist, Gerdhem. Study supervision: Karlsson.

\section{Supplemental Information}

Online-Only Content

Supplemental material is available with the online version of the article.

Supplemental Data. http://thejns.org/doi/suppl/10.3171/2016.2. SPINE16136

\section{Correspondence}

Fredrik Strömqvist, Department of Orthopaedics, Skane University Hospital, SE-205 02 Malmö, Sweden. email: fredrik. stromqvist@med.lu.se. 